\title{
Substituição das soldas estanho-chumbo na manufatura: Efeitos na saúde do trabalhador e no desempenho ambiental
}

\section{Substitution of tin-lead solders in manufacturing: Impacts on workers' health and on the environment}

\author{
Cecilia Maria Villas Bôas de Almeida ${ }^{1}$ \\ Marco Antonio Madureira ${ }^{1}$ \\ Biagio Fernando Giannetti ${ }^{1}$ \\ Silvia Helena Bonilla ${ }^{1}$
}

\begin{abstract}
Resumo: As soldas à base de estanho-chumbo $(63 \mathrm{Sn} / 37 \mathrm{~Pb})$ são largamente utilizadas no Brasil e no mundo. Este estudo aplica a avaliação em emergia em um fabricante de soldas brandas à base de estanho e chumbo e outros metais. O cálculo da emergia por unidade de três tipos de solda mostra que mais recursos são utilizados para produzir uma tonelada de soldas livres de chumbo do que para produzir soldas à base de estanho e chumbo. O indicador DALY (Disability Adjusted Life Years) foi utilizado para comparar as emissões na atmosfera dos três tipos de produção de soldas e os resultados apontam para a adoção das soldas à base de chumbo, quando se considera todo o ciclo de vida do produto. A diferença entre os resultados obtidos por avaliações locais e globais é discutida.

Palavras-chave: Emergia. Reciclagem. Estanho-chumbo. Soldas livres de chumbo. DALY.
\end{abstract}

\begin{abstract}
Tin-lead solders (Sn63-Pb37) have been widely used in Brazil and worldwide. This study evaluates the emergy in a company that manufactures soft solders based on tin, lead, and other metals. The calculation of emergy per unit of three types of solder showed that more resources are used to produce one ton of lead-free solders than those used to produce tin-lead solders. The DALY (Disability Adjusted Life Years) indicator was used to assess the emissions to air of three types of solder. The results favor the use of tin-lead solders when the whole product life-cycle is evaluated. The difference between the results obtained by local and global assessments is discussed.
\end{abstract}

Keywords: Emergy. Recycling. Tin-lead solders. Lead-free solders. DALY.

\section{Introdução}

As soldas à base de chumbo, assim como suas substitutas, são utilizadas para fixação de componentes eletrônicos na manufatura de circuitos eletroeletrônicos. A liga de estanho e chumbo (63Sn-37Pb) é uma das mais utilizadas para os processos de montagem de placas e circuitos eletrônicos, pois o chumbo possui um ótimo grau de molhagem e excelentes características no que se refere ao acabamento do produto final (GARCIA et al., 2009). Entretanto, desde o início da década passada, as soldas contendo chumbo vêm sofrendo crescente pressão das leis regulamentares, e uma alternativa para eliminar os riscos potenciais do chumbo é a substituição deste metal por outros componentes de liga menos nocivos à saúde humana (ITSUBO et al., 2003).

A substituição das soldas à base de chumbo vem ocorrendo desde 2004 principalmente na Europa e no
Japão (TURBINI et al., 2000). Embora a comunidade Europeia e alguns países asiáticos estejam utilizando as soldas livres de chumbo em grande escala, no Brasil as soldas estanho-chumbo são ainda largamente utilizadas. Isto ocorre não só devido a seu custo, como também pelo seu grau de "molhagem" e pelas suas propriedades físico-químicas, que agregam maior confiabilidade aos equipamentos eletroeletrônicos (PERASSI, 1994). A produção das soldas livres de chumbo ainda é pequena e ocorre, principalmente, devido à pressão das empresas estrangeiras. As ligas que têm o maior potencial para utilização pelas indústrias brasileiras são da família $\mathrm{Sn}-\mathrm{Ag}-\mathrm{Cu}$.

A maioria dos estudos encontrados na literatura, que tratam da substituição das soldas estanhochumbo, refere-se a aspectos ligados às propriedades físicas das junções efetuadas por esses tipos de

\footnotetext{
${ }^{1}$ Programa de Pós-graduação em Engenharia de Produção, Universidade Paulista - UNIP, Rua Dr. Bacelar, 1212, Mirandópolis, CEP 04026-002, São Paulo, SP, Brasil, e-mail: cmvbag@unip.br
} 
solda e aos problemas decorrentes nos produtos com elas manufaturados (ROMM; ABBOTT, 1998; DEUBZER et al., 2001; REUTER; VERHOEF, 2004; MA; CHEN, 2005). No que concerne à toxicidade do chumbo, a substituição destas soldas vem sendo estudada por diversos pesquisadores. Itsubo et al. (2003) avaliam o dano na saúde humana para discutir a efetividade da substituição do chumbo. Este autor considera a necessidade de estabelecer um fator de dano para melhorar a qualidade de avaliação e calcula as quantidades de chumbo emitidas desde a mineração até a produção de lingote em $0,6 \mathrm{~g}$ de chumbo emitido para cada quilograma de solda produzida. Segundo Ku (2003), as soldas alternativas sem chumbo são mais seguras em termos de toxicidade e impactos ambientais. A autora classifica os metais quanto à toxicidade e compara os resultados com a disponibilidade e oferta e a sua posição quanto aos impactos ambientais na extração. A autora oferece um ranking final, com base no qual recomenda a substituição das ligas contendo chumbo. Okamoto et al. (2005) avaliam a substituição do chumbo por antimônio, bismuto, prata, cobre, índio e zinco e recomendam a utilização das soldas livres de chumbo como a melhor solução no presente.

De outro lado, Turbini et al. (2000) relatam que é importante refletir sobre o impacto ambiental de produtos eletrônicos livres de chumbo em todo o seu ciclo de vida. Isto inclui fatores como: ligas disponíveis, considerações sobre o processamento, a utilização da energia, além da contaminação das águas subterrâneas. Muitos pesquisadores argumentam sobre o aumento significativo do consumo de energia elétrica para os processos de soldagem com as ligas livres de chumbo, mas concluem que a eliminação do chumbo e o custo efetivo dessa eliminação proporcionarão benefícios operacionais e de mercado para os fabricantes eletrônicos (CIOCCI; PECHT, 2006; TURBINI, 2007). Fujimo e Suga (2003), empregando a Avaliação de Ciclo de Vida (ACV) simplificada, relatam que a toxicidade do chumbo e o valor de consumo de energia são os maiores impactos causados pelas soldas para o meio ambiente. Zhou e Schoenung (2007) relatam que a solda sem chumbo tem impacto ambiental global comparável ao da solda de estanho-chumbo convencional, quando todo o ciclo de vida é levado em conta. A substituição das soldas à base de estanho e chumbo causa a diminuição da toxicidade, mas também um aumento de consumo de energia dos fornos de processamento. As afirmações de Zhou e Schoenung (2008) são complementadas pelas pesquisas realizadas por Reuter e Verhoef (2004). Segundo estes autores, os resultados e argumentos mudarão quando os desenvolvimentos tecnológicos (nos fornos de recuperação e na manufatura das placas eletrônicas) levarem à utilização efetiva das soldas livres de chumbo.
Há, ainda, algumas avaliações mais abrangentes que avaliam o ciclo de vida e impactos ambientais de soldas com e sem chumbo (SEGERBERG; HEDEMALM, 1996; SOCOLOF; GEIBIG, 2005; ANDRAE et al., 2008). Socolof e Geibig (2005) apresentam os resultados da ACV (Avaliação de Ciclo de Vida) para a análise individual de cada solda e mostram que a solda de estanho-chumbo tem o maior indicador de impacto em quatro categorias (câncer ocupacional, doenças ocupacionais crônicas não cancerosas, saúde pública e doenças crônicas não cancerosas no público). Já as soldas livres de chumbo têm o maior indicador de impacto nas doze categorias restantes, relativamente a: recursos não renováveis e renováveis, utilização de energia elétrica e GLP (gás liquefeito de petróleo), uso espacial de aterros, aquecimento global, camada de ozônio, nevoeiro fotoquímico, acidificação, particulados no ar, qualidade da água e contaminação pública.

Observa-se na revisão da literatura que há ainda controvérsias quanto à substituição das ligas de estanho-chumbo. Enquanto alguns pesquisadores destacam a toxicidade do chumbo e os danos causados à saúde humana na fabricação das soldas e na manufatura dos equipamentos eletroeletrônicos (ITSUBO et al., 2003; KU et al., 2003, OKAMOTO et al., 2005), outros destacam as desvantagens relativas à substituição, como o aumento do consumo de energia elétrica e do uso de recursos não renováveis (SEGERBERG; HEDEMALM, 1996; SOCOLOF; GEIBIG, 2005; ANDRAE et al., 2008; ZHOU; SCHOENUNG, 2008).

Neste estudo, a síntese em emegia é aplicada para avaliar um fabricante de soldas brandas à base de estanho-chumbo e outros metais. A avaliação em emergia realizada na Cast Metais e Soldas Ltda. tem como objetivo dar suporte para o gerenciamento da empresa no que se refere à escolha das melhores práticas de produção, à produtividade $\mathrm{e}$ à competitividade, assim como à gestão dos recursos naturais não renováveis utilizados. O indicador DALY (Disability Adjusted Life Years) foi empregado para complementar a avaliação em emergia e estimar o dano à saúde humana devido às emissões ao ar causadas pela produção dos três tipos de solda. A avaliação que agrega estes dois indicadores permite determinar o efeito da produção de soldas (63Sn-37Pb, 99Sn-0,3Ag-0,7Cu e 96,5Sn-3Ag-0,5Cu) no desempenho ambiental da empresa e o dano causado à saúde do trabalhador devido às emissões de poluentes na cadeia produtiva.

\section{Métodos}

\subsection{A empresa em estudo}

A empresa brasileira Cast Metais e Soldas Ltda. opera desde 1999 e fabrica uma linha completa de soldas em ânodos, barras, arames, vergas, fios sólidos 
com e sem resina, em várias formas, tamanhos e diâmetros.

A produção de solda atual está dividida em mais ou menos $90 \%$ em soldas estanho-chumbo e $10 \%$ para livres de chumbo, que são produzidas de acordo com a demanda do mercado brasileiro.

A empresa é certificada pelo ISO9001:2008 desde setembro de 2006 e está em processo de implantação da ISO14001:2004.

\subsection{A síntese em emergia}

Emergia pode ser definida como a memória da energia ou a energia total incorporada em um produto, processo ou serviço. É a quantidade de energia necessária, de forma direta ou indireta, para obter um produto (bem ou serviço) em um determinado processo, sendo sua unidade expressa em seJ (joule de energia solar). O uso de uma única unidade para a qual são convertidos os diversos tipos de energia permite somar todas as contribuições de energia utilizadas para a obtenção de um determinado produto ou serviço. Define-se a transformidade como a quantidade de energia solar empregada, direta e/ou indiretamente, na obtenção de um joule de um determinado produto (bem ou serviço), sendo sua unidade expressa em seJ/J (joule de energia solar por Joule). A transformidade fornece uma medida da concentração de emergia e pode ser considerada como um indicador de qualidade. Os valores de emergia e transformidade dependem do material e da energia utilizados nas diversas etapas necessárias para a obtenção do produto ou serviço e, por este motivo, variam de acordo com a matéria-prima selecionada, com o tipo de energia empregado na produção e com a eficiência do sistema produtivo.

A avaliação em emergia permite a conversão de todas as contribuições recebidas pelo sistema de produção (metais, energia, óleo, dinheiro e informações) em uma única métrica: a energia solar joule (sej). Os sistemas em estudo podem ser comparados relativamente à sua eficiência em utilização de recursos utilizados, produtividade, impacto ambiental e sustentabilidade global (GIANNETTI; ALMEIDA; BONILLA, 2010; GIANNETTI; BARRELLA; BONILLA, 2007; GIANNETTI et al., 2009; BARRELLA; ALMEIDA; GIANNETTI, 2005; ALMEIDA et al., 2010a, b; BONILLA et al., 2010).

O procedimento de avaliação do sistema em estudo foi executado por meio de coleta de dados em documentos formais de aquisição, nos anos 2006 e 2007, e utilizados para os seguintes passos:

- Definição dos limites para a investigação;

- Estudo do contexto em que o sistema está inserido e execução do balanço de massa;

- Construção de diagramas de fluxos de energia;

- Construção da tabela em emergia com dados coletados; e
- Discussão para ações futuras de gerenciamento ambiental do processo de produção.

A pesquisa de campo foi efetuada tomando-se como estudo de caso a empresa Cast Metais e Soldas Ltda. Para cada liga, as quantidades de eletricidade consumida, o gás liquefeito de petróleo (GLP), papel e papelão, óleos lubrificantes, trabalho humano, carretéis, trapos de algodão foram calculadas pelo consumo médio dos anos 2006 e 2007. As quantidades dos ácidos utilizados para análise dos elementos de liga no laboratório químico foram calculadas com base nas notas fiscais referentes às compras nos mesmos anos. O consumo da água foi calculado pela consulta das contas de consumo, assim como as quantidades mensais de metais, materiais, insumos utilizados na implantação do sistema. A emergia associada a cada entrada de material no sistema é calculada de acordo com a Equação 1.

$$
\mathrm{Em}=\mathrm{Q} \times \mathrm{Em} / \mathrm{un} .
$$

Em que Q é a quantidade de material ou energia utilizada no processo de fabricação das soldas e Em/un., a emergia por unidade de cada quantidade.

\subsection{O indicador de DALY}

A fim de calcular os efeitos na vida do trabalhador da emissão de gases de chumbo na produção das soldas estudadas, foi utilizado o indicador DALY (Disability Adjusted Life Years). Este indicador foi originalmente desenvolvido para a Organização Mundial de Saúde (OMS) e calcula os efeitos de emissões na saúde humana, que levam à enfermidade ou morte (MIRAGLIA; SALDIVA, 2005). Considera-se que, em geral, os contaminantes contribuem para o indicador DALY com as duas porções, já que os efeitos de exposição a certos contaminantes não só causam mortalidade como um período com incapacidade antes da ocorrência da morte. A probabilidade de redução de vida devido à exposição a um contaminante em particular, inclui a probabilidade de morte causada por dano à saúde (AVP, anos de vida perdidos) e o estado mórbido, isto é, os efeitos na saúde que não levam para a morte imediata, mas causam dor, sofrimento ou uma diminuição na qualidade de vida (AVI, anos vividos com incapacidade).

Baseado nas concentrações dos contaminantes emitidos, é possível determinar a quantidade de uma substância a que pessoas são expostas e calcular quantos anos de vida são perdidos por inaptidão ou por morte prematura. A análise do dano à qualidade de vida ou morte prematura é expressa como uma unidade de dano, neste caso, o indicador DALY. As emissões por quilograma de solda produzida em todo o ciclo de vida das soldas foram retiradas de Socolof e Geibig (2005) e os valores do indicador DALY 
para cada tipo de emissão de Itsubo et al. (2003) e de Zhang et al. (2009).

A Equação 2 apresenta o cálculo da emergia correspondente ao dano para a saúde humana ou ao número de anos perdidos $\left(\mathrm{Em}_{\mathrm{DANO}}\right)$ devido à emissão de um contaminante (UKIDWE; BAKSHI, 2004).

$$
\mathrm{Em}_{\text {DANO }}=\mathrm{mj} \times \mathrm{DALY} \times \mathrm{Em}_{\text {BRASIL }}
$$

Em que mj é a massa de substância emitida (kg/ano); o indicador DALY apresenta os anos de vida perdidos dependendo da substância emitida (anos perdidos per capta por $\mathrm{kg}$ ); Em $_{\text {BRASIL }}$ é a emergia do Brasil, dividida por número de habitantes, $1,47 \times 10^{16} \mathrm{sej} / \mathrm{habitante}$ (COELHO; ORTEGA; COMAR, 2002).

Para melhor compreenderem-se os resultados, os valores obtidos na avaliação em emergia e os do indicador DALY foram convertidos em moeda corrente empregando-se o valor estatístico do impacto na vida humana (MIRAGLIA; SALDIVA, 2005). Este valor, no Brasil, é de US\$ 7.700,00 por ano (MIRAGLIA; SALDIVA, 2005) e foi estimado pelo levantamento com gastos com a saúde humana e os custos de hospitalizações.

\section{Resultados e discussão}

\subsection{Primeira avaliação de aspectos e impactos}

A Cast Metais e Soldas Ltda. obteve a certificação pela Norma ISO9001: 2000, em setembro de 2006, passando, a partir dessa data, a adaptar seus processos para a obtenção da certificação ISO14001. Procedeu-se a uma análise formal de aspecto e impacto ambiental, conforme exigido pela ISO 14001:2004 em seu item 4.3.1 - Aspectos ambientais. Para tanto, foi elaborado o procedimento de avaliação de aspectos e impactos ambientais e requisitos legais, que prevê o preenchimento do registro de avaliação de aspectos e impactos. A falta deste procedimento, assim como a não emissão do registro de análise inicial do Sistema de Gestão Ambiental, segundo as normas ISO 14001:2004, implica a não certificação da empresa.

Primeiramente, foi estabelecida a área de abrangência da avaliação, assim como as interfaces com outros ambientes e outras partes interessadas (órgãos públicos). $\mathrm{O}$ "Inventário Ambiental” incluiu: matérias-primas químicas e materiais auxiliares de risco; efluentes líquidos e gasosos; resíduos sólidos; produtos intermediários/subprodutos e produtos acabados; e recursos naturais consumidos (água, eletricidade, combustíveis, gás, etc.). Todos os documentos e registros gerados neste levantamento foram retidos para auditoria, como memorial descritivo. Depois de identificar o maior número possível de impactos ambientais reais e potenciais, positivos e negativos, associados a cada aspecto identificado.

Depois da definição da probabilidade de Ocorrência de Impacto e da Gravidade do Impacto, que é utilizada para a votação da equipe de gestão do sistema, determinou-se o Grau de Significância de acordo com o critério apresentado na Tabela 1.

A empresa realizou uma Primeira Avaliação de Aspectos e Impactos (Tabela 2), que apresenta os resultados votados pelo grupo de implantação do Sistema de Gestão Ambiental, identificando os impactos classificados de acordo com o grau de significância para estabelecer metas, controles operacionais, monitoramento e medição ou planos de emergência. Os aspectos avaliados referem-se à poluição do solo e à escassez de recursos naturais. Observa-se na Tabela 2 que, para os aspectos referentes à poluição do solo, a empresa emprega controles operacionais para disposição de seus resíduos sólidos, seja pela separação e envio para coleta seletiva, seja pelo descarte regulamentado pela Companhia de Tecnologia de Saneamento Ambiental (Cetesb) por meio do CADRI (Certificado de Aprovação de Destinação de Resíduos Industriais). O CADRI é o instrumento que aprova o encaminhamento de resíduos sólidos industriais a locais de reprocessamento, armazenamento, tratamento ou disposição final.

Para os aspectos referentes à escassez de recursos naturais (Tabela 2), o grupo formado para implementação do Sistema de Gestão Ambiental (SGA) estabeleceu, após brainstorming, objetivos e metas visando a redução do consumo de eletricidade e GLP, além da redução do consumo da água, apesar do grau de significância baixo. Com esta Primeira Avaliação, iniciou-se o monitoramento dos processos que acabaram gerando os dados utilizados para a Avaliação em Emergia. Porém, constatou-se que, com a Primeira Avaliação, não é possível decidir sobre a utilização de soldas com ou sem chumbo.

Tabela 1. Grau de significância obtido pela multiplicação da gravidade do impacto pela probabilidade de ocorrência do impacto.

\section{Probabilidade de ocorrência de impacto}

\begin{tabular}{llccc} 
& & (3) Alta & (2) Média & (1) Baixa \\
\multirow{3}{*}{ Gravidade do impacto } & (3) Alta & 9 & 6 & 3 \\
& (2) Média & 6 & 4 & 2 \\
& (1) Baixa & 3 & 2 & 1 \\
\hline
\end{tabular}


Tabela 2. Resultados da Primeira Avaliação de Aspectos e Impactos da Cast Metais e Soldas Ltda.

\begin{tabular}{|c|c|c|c|c|c|c|}
\hline \multirow[b]{2}{*}{ Aspecto } & \multicolumn{2}{|c|}{ Ambiente de interação } & \multirow[b]{2}{*}{ Probabilidade } & \multirow[b]{2}{*}{ Gravidade } & \multirow[b]{2}{*}{$\begin{array}{c}\text { Grau de } \\
\text { significância }\end{array}$} & \multirow[b]{2}{*}{$\begin{array}{c}\text { Controle } \\
\text { operacional } \\
\text { existente }\end{array}$} \\
\hline & $\begin{array}{l}\text { Poluição do } \\
\text { solo }\end{array}$ & $\begin{array}{c}\text { Escassez } \\
\text { de recursos } \\
\text { naturais } \\
\end{array}$ & & & & \\
\hline Consumo de água & & $\mathbf{X}$ & 1 & 2 & 2 & - \\
\hline $\begin{array}{l}\text { Consumo de energia } \\
\text { elétrica }\end{array}$ & & $\mathbf{X}$ & 3 & 2 & 6 & - \\
\hline Consumo de GLP & & $\mathbf{X}$ & 2 & 2 & 4 & - \\
\hline $\begin{array}{l}\text { Descarte de papel e } \\
\text { papelão }\end{array}$ & $\mathbf{X}$ & & 1 & 2 & 2 & Coleta Seletiva \\
\hline $\begin{array}{l}\text { Descarte de } \\
\text { componentes mecânicos } \\
\text { de equipamentos }\end{array}$ & $\mathbf{X}$ & & 1 & 3 & 3 & CADRI \\
\hline $\begin{array}{l}\text { Descarte de copos } \\
\text { plásticos }\end{array}$ & $\mathbf{X}$ & & 1 & 3 & 3 & Coleta Seletiva \\
\hline $\begin{array}{l}\text { Descarte de } \\
\text { componentes elétricos } \\
\text { de equipamentos }\end{array}$ & $\mathbf{X}$ & & 1 & 3 & 3 & CADRI \\
\hline $\begin{array}{l}\text { Descarte de } \\
\text { equipamentos obsoletos }\end{array}$ & $\mathbf{X}$ & & 1 & 2 & 2 & Coleta Seletiva \\
\hline $\begin{array}{l}\text { Descarte de papel } \\
\text { higiênico }\end{array}$ & $\mathbf{X}$ & & 1 & 3 & 3 & Coleta Seletiva \\
\hline $\begin{array}{l}\text { Descarte de panos de } \\
\text { limpeza }\end{array}$ & $\mathbf{X}$ & & 1 & 3 & 3 & CADRI \\
\hline $\begin{array}{l}\text { Descarte de pilhas e } \\
\text { baterias }\end{array}$ & $\mathbf{X}$ & & 1 & 3 & 3 & Coleta Seletiva \\
\hline Descarte de lâmpadas & $\mathbf{X}$ & & 1 & 3 & 3 & CADRI \\
\hline $\begin{array}{l}\text { Borras de Estanho } \\
(\mathrm{Sn} / \mathrm{Pb} ; \mathrm{Sn} / \mathrm{Cu} ; \mathrm{Sn} / \mathrm{Ag} ; \\
\mathrm{Sn} / \mathrm{Zn} ; \mathrm{Sn} / \mathrm{Sb})\end{array}$ & $\mathbf{X}$ & & 1 & 3 & 3 & CADRI \\
\hline
\end{tabular}

\subsection{Avaliação em emergia}

Para a avaliação em emergia na Cast Metais Soldas Ltda., foram estabelecidos os fluxos do processo com as entradas e saídas em massa, para a produção das três soldas. A Figura 1 mostra o fluxo de massa para a liga de $63 \mathrm{Sn}-37 \mathrm{~Pb}$.

Para a produção de $946 \mathrm{t}$ da liga de solda 63Sn-37Pb, $237 \mathrm{t}$ de borra retornam dos clientes e $124 \mathrm{t}$ de sucata são captadas no mercado. O processo de recuperação interna tem um rendimento médio de 55\% em massa e recupera a borra dos clientes e a sucata num total de 198 toneladas. Os restantes $45 \%$ são enviados para tratamento externo em um fornecedor homologado pelo órgão oficial do Estado (CETESB), o que gera um retorno de $114 \mathrm{t}$ da liga de $63 \mathrm{Sn}-37 \mathrm{~Pb}$.

A Figura 2 apresenta o diagrama de energia do processo de produção das soldas baseadas em estanho e outros metais. Cada fluxo corresponde a uma linha na tabela de avaliação em emergia (Tabela 3 ), em que os fluxos em energia, materiais e serviços quantificados em suas unidades correspondentes são convertidos em fluxos de emergia, quando multiplicados por sua emergia por unidade (sej/un.).

Para a solda $63 \mathrm{Sn}-37 \mathrm{~Pb}$, o estanho participa com $71,7 \%$ do total em emergia, o chumbo com $11,9 \%$ sej/sej e a sucata com $16,4 \%$ sej/sej. O total em emergia para produzir $946 \mathrm{t}$ deste tipo de solda é $9,47 \times 10^{20}$ sej/ano. Quando se avaliam as soldas livres de chumbo, observa-se que o estanho participa com $95 \%$ do total de emergia na solda $96,5 \mathrm{Sn}-3 \mathrm{Ag}-0,5 \mathrm{Cu}$ e com $96,8 \%$ para a solda $99 \mathrm{Sn}-0,3 \mathrm{Ag}-0,7 \mathrm{Cu}$. O total em emergia para produzir $13,7 \mathrm{t}$ da solda $96,5 \mathrm{Sn}-3 \mathrm{Ag}-0,5 \mathrm{Cu}$ é de $1,69 \times 10^{19} \mathrm{sej} /$ ano e utilizam-se $9,13 \times 10^{19} \mathrm{sej} / \mathrm{ano}$ para produzir $72 \mathrm{t}$ da solda $99 \mathrm{Sn}-0,3 \mathrm{Ag}-0,7 \mathrm{Cu}$. Estes resultados evidenciam o impacto causado pelo aumento do consumo de estanho nas ligas livres de chumbo. Para os três tipos de solda, a emergia investida para a implantação da fábrica está muito aquém daquela exigida pelo processo de operação.

Podem-se comparar os resultados obtidos pela avaliação em emergia com aqueles obtidos na primeira avaliação de aspectos e impactos ambientais em alguns pontos. A Tabela 4 apresenta a comparação do grau de significância atribuído para estes três 


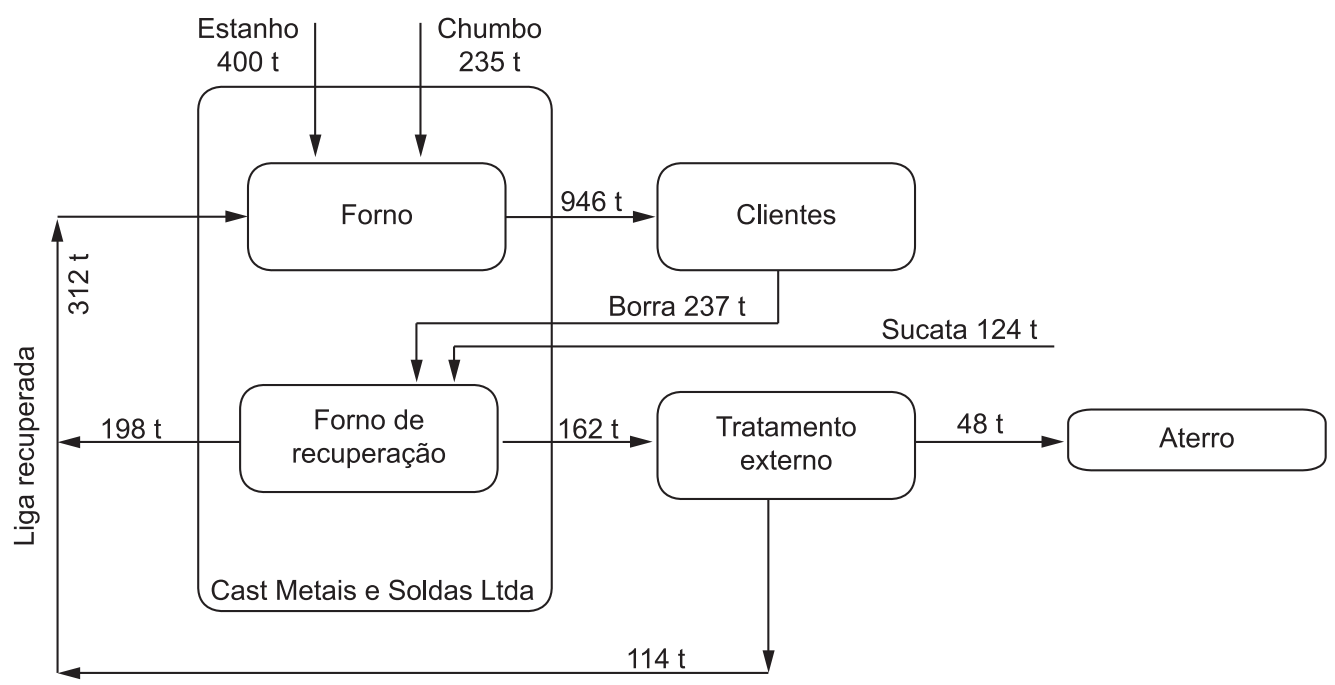

Figura 1. Balanço de massa para a solda 63Sn-37Pb. Valores médios para 2006/2007.

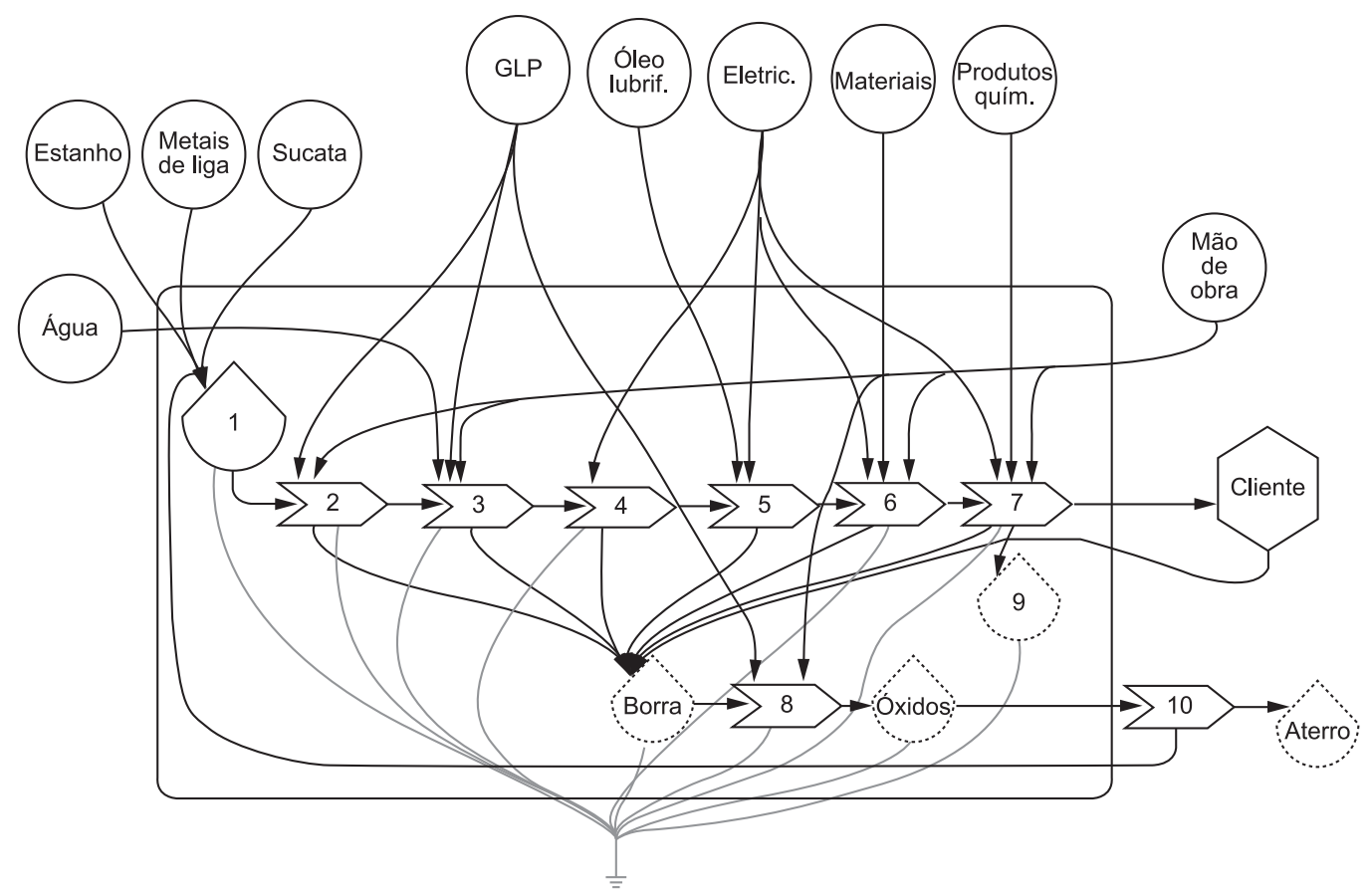

Figura 2. Diagrama de energia da produção de soldas brandas à base de estanho: (1) Estoque de recebimento de matéria-prima, (2) Forno de fundição da liga, (3) Coquilhamento dos tarugos, (4) Extrusão do fio primário, (5) Trefilação dos fios, (6) Bobinagem em carretéis plásticos e embalagem, (7) Laboratório químico, (8) Forno para recuperação de borras, (9) Efluente de laboratório e (10) Empresa de recuperação de óxidos.

aspectos comparados com os resultados da avaliação em emergia. Embora o consumo de eletricidade tenha sido eleito, pelo grupo de implantação do SGA, como o consumo de impacto mais significativo na produção (Tabela 1), pela avaliação em emergia, o GLP apresenta-se com a maior contribuição, seguido pelo uso da água. O consumo de eletricidade é a entrada que menos contribui para o total em emergia, o que contraria a percepção dos gestores.

\subsection{Avaliação da substituição total da solda estanho-chumbo}

Segundo a tendência dos mercados globais, em particular os europeus e o japonês, haverá a substituição total da solda estanho-chumbo. Para simular esta condição, considerou-se a quantidade de produção das soldas livres de chumbo substituindo totalmente a solda $63 \mathrm{Sn}-37 \mathrm{~Pb}$, que é a que atualmente representa $90 \%$ da produção da empresa (Tabela 5). 
Tabela 3. Avaliação em Emergia da produção anual de soldas $63 \mathrm{Sn}-37 \mathrm{~Pb}$.

\begin{tabular}{|c|c|c|c|c|c|c|}
\hline \multirow{2}{*}{\multicolumn{2}{|c|}{$\begin{array}{l}\text { Itens para produção } \\
\text { da Liga } 67 \mathrm{Sn}-37 \mathrm{~Pb}\end{array}$}} & \multirow[t]{3}{*}{ Quant. $^{(a)}$} & \multirow[t]{3}{*}{ Un. } & \multirow{2}{*}{$\begin{array}{c}\begin{array}{c}\text { Emergia por } \\
\text { unidade }^{(b)}\end{array} \\
\text { (sej/unid.) }\end{array}$} & \multicolumn{2}{|c|}{ Emergia Solar } \\
\hline & & & & & sej/ano & $\%$ (sej/sej) \\
\hline \multicolumn{5}{|c|}{ Operação } & & \\
\hline 1 & Estanho & $4,00 \times 10^{8}$ & $\mathrm{~g}$ & $1,70 \times 10^{12}$ & $6,79 \times 10^{20}$ & 71,7 \\
\hline 2 & Chumbo & $2,35 \times 10^{8}$ & $\mathrm{~g}$ & $4,80 \times 10^{11}$ & $1,13 \times 10^{20}$ & 11,9 \\
\hline 3 & Sucata & $1,24 \times 10^{8}$ & $\mathrm{~g}$ & $1,25 \times 10^{12}$ & $1,55 \times 10^{20}$ & 16,4 \\
\hline 4 & Retorno de borra $^{(\mathrm{c})}$ & $2,37 \times 10^{8}$ & $\mathrm{~g}$ & $1,25 \times 10^{12}$ & $2,95 \times 10^{20}$ & 31,2 \\
\hline 5 & Energia elétrica & $6,07 \times 10^{9}$ & $\mathrm{~J}$ & $1,60 \times 10^{5}$ & $1,16 \times 10^{12}$ & $<0,1$ \\
\hline 6 & Gás GLP & $1,05 \times 10^{11}$ & $\mathrm{~J}$ & $4,80 \times 10^{4}$ & $5,03 \times 10^{15}$ & $<0,1$ \\
\hline 7 & Papelão & $1,24 \times 10^{6}$ & $\mathrm{~g}$ & $3,90 \times 10^{9}$ & $4,83 \times 10^{15}$ & $<0,1$ \\
\hline 8 & Óleo & $1,84 \times 10^{9}$ & $\mathrm{~J}$ & $6,60 \times 10^{4}$ & $1,21 \times 10^{14}$ & $<0,1$ \\
\hline 9 & Mão de obra & $9,80 \times 10^{10}$ & $\mathrm{~J}$ & $4,49 \times 10^{6}$ & $1,38 \times 10^{17}$ & 0,1 \\
\hline 10 & Carretéis plásticos & $1,90 \times 10^{7}$ & $\mathrm{~g}$ & $3,80 \times 10^{8}$ & $7,21 \times 10^{15}$ & $<0,1$ \\
\hline 11 & Panos de limpeza & $2,04 \times 10^{3}$ & $\mathrm{~g}$ & $2,31 \times 10^{10}$ & $4,71 \times 10^{13}$ & $<0,1$ \\
\hline 12 & Ácido Clorídrico & $8,91 \times 10^{4}$ & $\mathrm{~g}$ & $1,00 \times 10^{9}$ & $8,91 \times 10^{13}$ & $<0,1$ \\
\hline 13 & Ácido Sulfúrico & $3,47 \times 10^{4}$ & $\mathrm{~g}$ & $1,00 \times 10^{9}$ & $3,47 \times 10^{13}$ & $<0,1$ \\
\hline 14 & Ácido Nítrico & $1,59 \times 10^{4}$ & $\mathrm{~g}$ & $1,00 \times 10^{9}$ & $1,59 \times 10^{13}$ & $<0,1$ \\
\hline 15 & Ácido Fluorídrico & $5,85 \times 10^{3}$ & $\mathrm{~g}$ & $1,00 \times 10^{9}$ & $5,85 \times 10^{12}$ & $<0,1$ \\
\hline 16 & Consumo de água & $8,09 \times 10^{7}$ & $\mathrm{~g}$ & $6,64 \times 10^{5}$ & $7,02 \times 10^{14}$ & $<0,1$ \\
\hline \multicolumn{7}{|c|}{ Implantação } \\
\hline 17 & Máquinas e Equipamentos & $1,26 \times 10^{4}$ & $\mathrm{~g}$ & $4,10 \times 10^{9}$ & $1,22 \times 10^{15}$ & $<0,1$ \\
\hline 18 & Caixas metálicas para manuseio de borras & $3,99 \times 10^{3}$ & $\mathrm{~g}$ & $2,77 \times 10^{9}$ & $1,43 \times 10^{14}$ & $<0,1$ \\
\hline 19 & Cadinho & $3,78 \times 10^{4}$ & $\mathrm{~g}$ & $3,06 \times 10^{9}$ & $1,16 \times 10^{14}$ & $<0,1$ \\
\hline 20 & Cadinho reserva & $1,26 \times 10^{4}$ & $\mathrm{~g}$ & $3,06 \times 10^{9}$ & $3,85 \times 10^{13}$ & $<0,1$ \\
\hline 21 & Estruturas Metálicas do Telhado & $2,98 \times 10^{7}$ & $\mathrm{~g}$ & $2,77 \times 10^{9}$ & $8,25 \times 10^{16}$ & $<0,1$ \\
\hline 22 & Construção civil & $2,12 \times 10^{6}$ & $\mathrm{~g}$ & $1,54 \times 10^{9}$ & $3,26 \times 10^{15}$ & $<0,1$ \\
\hline \multirow[t]{2}{*}{23} & Mão de Obra & $6,56 \times 10^{9}$ & $\mathrm{~g}$ & $4,49 \times 10^{6}$ & $2,95 \times 10^{16}$ & $<0,1$ \\
\hline & & & & Emergia total & $9,47 \times 10^{20}$ & \\
\hline
\end{tabular}

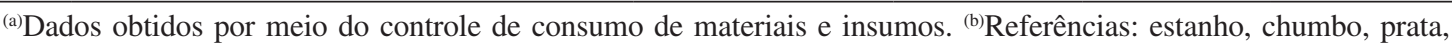
cobre, borra e sucata (COHEN et al., 2007); eletricidade (TILLEY, 2000); gás liquefeito de petróleo (WANG; ZHANG, 2005); papelão (ULGIATI; BROWN, 2002); óleo lubrificante (ODUM, 1996); trabalho no Brasil (COELHO; ORTEGA; COMAR, 2002); plástico (BRANT, 2002); limpando panos, ácido clorídrico, ácido sulfúrico, ácido nítrico e ácido fluorídrico (ODUM, 1996); água (CARUSO et al., 2001); máquinas e equipamentos, caixas de metal, cadinhos, telhados de metal e concreto do edifício industrial (BROWN; BURANAKHARN, 2003). Quando necessário, os valores da emergia por unidade foi multiplicado por 1,68 para a obtenção da emergia total na base $15,83 \times 10^{24}$ sej/ano (ODUM; BROWN; BRANDT-WILLIAMS, 2000). ${ }^{(\mathrm{c})}$ Não contabilizado para evitar dupla contagem.

Pode-se notar que o aumento total na emergia da empresa é de aproximadamente $23 \% \mathrm{sej} / \mathrm{sej}$ para o caso da substituição total da liga estanho-chumbo por qualquer uma das ligas livres de chumbo. Ou seja, mais recursos são usados para produzir uma tonelada de solda livre de chumbo do que para produzir a solda tradicional que contém chumbo. É importante ressaltar que a contabilidade em emergia considera todos os recursos utilizados direta ou indiretamente para a obtenção de um produto ou serviço. Deste modo, em termos de eficiência na utilização de recursos, a solda $63 \mathrm{Sn}-37 \mathrm{~Pb}$ é a melhor opção. Este resultado está de acordo com os resultados obtidos por Socolof e Geibig (2005) utilizando a ACV (Tabela 6). Estes autores contabilizaram as quantidades de recursos não renováveis utilizados para a fabricação de $1 \mathrm{~kg}$ de solda com e sem chumbo e constataram que até a etapa de manufatura, a fabricação de soldas livres de chumbo emprega 3,5 vezes mais recursos que a solda 63Sn-37Pb. No total do ciclo de vida, a fabricação das soldas livres de chumbo consome 3,2 vezes mais recursos não renováveis que a solda tradicional que contém chumbo. É importante ressaltar que a contabilidade em emergia avalia, não somente a quantidade de materiais empregados para a produção de um bem ou serviço, mas também sua qualidade. Quando se compara o aumento no total de emergia para a produção de soldas livres de chumbo com o uso 
Tabela 4. Comparação do grau de significância (análise de aspectos e impactos conforme ISO 14001:2004) e a contribuição em emergia das três soldas em estudo $(*)$.

\begin{tabular}{lcccc}
\hline \multirow{2}{*}{ Consumo } & $\begin{array}{c}\text { Grau de } \\
\text { significância }\end{array}$ & \multicolumn{3}{c}{$\begin{array}{c}\text { Emergia } \\
\left(\mathbf{1 0} \mathbf{1}^{\mathbf{1 3}} \times \text { sej/ano }\right)\end{array}$} \\
\cline { 3 - 5 } & 2 & $\mathbf{6 3 S n - 3 7 P b}$ & $\mathbf{9 6 , 5 S n - 3 A g - 0 . 5 C u}$ & $\mathbf{9 9 S n - 0 , 3 A g - 0 . 7 C u}$ \\
\hline Água & 2 & 0,11 & 5 & 26 \\
Eletricidade & $\mathbf{6}$ & $\mathbf{5 0 3}$ & 0,08 & 0,08 \\
GLP & 4 & $\mathbf{3 7}$ & $\mathbf{1 8 6}$ \\
\hline
\end{tabular}

(*) os dados obtidos para a solda $63 \mathrm{Sn}-37 \mathrm{~Pb}$ foram retirados da Tabela 3 . As tabelas de dados referentes às soldas 96,5Sn-3Ag-0.5Cu e 99Sn-0,3Ag-0.7Cu podem ser encontradas em Madureira (2009).

Tabela 5. Simulação da substituição total da soldas estanho-chumbo pelas livres de chumbo.

\begin{tabular}{|c|c|c|c|c|}
\hline Solda & Quantidade & Unidade & $\begin{array}{c}\text { Emergia por unidade / } \\
\text { (sej/unidade) }\end{array}$ & $\begin{array}{c}\text { Emergia / } \\
\text { (sej/ano) }\end{array}$ \\
\hline \multicolumn{5}{|l|}{ 63Sn-37Pb } \\
\hline Estanho & $4,00 \times 10^{8}$ & $\mathrm{~g}$ & $1,70 \times 10^{12}$ & $6,79 \times 10^{20}$ \\
\hline Chumbo & $2,35 \times 10^{8}$ & g & $4,80 \times 10^{11}$ & $1,13 \times 10^{20}$ \\
\hline \multirow[t]{2}{*}{ Sucata } & $1,24 \times 10^{8}$ & $\mathrm{~g}$ & $1,25 \times 10^{12}$ & $1,55 \times 10^{20}$ \\
\hline & & & Emergia total & $9,47 \times 10^{20}$ \\
\hline \multicolumn{5}{|c|}{ 96,5Sn-3Ag-0,5Cu } \\
\hline Estanho & $6,76 \times 10^{8}$ & $\mathrm{~g}$ & $1,70 \times 10^{12}$ & $1,15 \times 10^{21}$ \\
\hline Prata & $2,10 \times 10^{7}$ & $\mathrm{~g}$ & $4,50 \times 10^{11}$ & $9,45 \times 10^{18}$ \\
\hline Cobre & $3,50 \times 10^{6}$ & $\mathrm{~g}$ & $9,80 \times 10^{10}$ & $3,43 \times 10^{17}$ \\
\hline \multirow[t]{2}{*}{ Sucata } & $4,15 \times 10^{5}$ & $\mathrm{~g}$ & $1,65 \times 10^{12}$ & $6,87 \times 10^{17}$ \\
\hline & & & Emergia total & $1,16 \times 10^{21}$ \\
\hline \multicolumn{5}{|c|}{ 99Sn-0,3Ag-0,7Cu } \\
\hline Estanho & $6,92 \times 10^{8}$ & $\mathrm{~g}$ & $1,70 \times 10^{12}$ & $1,18 \times 10^{21}$ \\
\hline Prata & $2,10 \times 10^{6}$ & $\mathrm{~g}$ & $4,50 \times 10^{11}$ & $9,44 \times 10^{17}$ \\
\hline Cobre & $4,89 \times 10^{6}$ & $\mathrm{~g}$ & $9,80 \times 10^{10}$ & $4,79 \times 10^{17}$ \\
\hline \multirow[t]{2}{*}{ Sucata } & $1,79 \times 10^{6}$ & $\mathrm{~g}$ & $1,69 \times 10^{12}$ & $3,02 \times 10^{18}$ \\
\hline & & & Emergia total & $1,18 \times 10^{21}$ \\
\hline
\end{tabular}

de recursos não renováveis para a fabricação de $1 \mathrm{~kg}$ de solda, pode-se constatar que o maior consumo de materiais se dá na fase de extração/beneficiamento. Nesta fase, são empregados materiais de menor emergia por unidade (ou menor qualidade), o que implica em aumento de apenas $23 \%$ na emergia total.

\subsection{Avaliação da substituição das soldas $63 \mathrm{Sn}-37 \mathrm{~Pb}$ com relação aos danos à saúde do trabalhador}

Os esforços mundiais voltados à substituição das soldas de estanho-chumbo na manufatura e na indústria eletroeletrônica devem-se, principalmente, à tentativa de eliminar os danos potenciais à saúde humana causados pela exposição aos vapores de chumbo na manufatura e na montagem dos circuitos eletrônicos. O indicador DALY permite avaliar o dano causado pela emissão de poluentes como gases de chumbo, $\mathrm{CO}_{2}, \mathrm{SO}_{\mathrm{x}}$ e material particulado (MP). Itsubo et al. (2003) reportaram que a emissão de chumbo é de
0,6 g de chumbo por quilograma de solda produzida, desde a extração até a manufatura. Neste trabalho, esta emissão foi atribuída à etapa de manufatura e considerou-se a mesma quantidade emitida, tanto para a manufatura como para a etapa de aplicação da solda. A Cast Metais e Soldas Ltda. utiliza EPIs (Equipamentos de Proteção Individual), bem como emprega EPCs (Equipamentos de Proteção Coletiva) para captação dos gases e filtragem através de sistema exaustor com mangas, para recolhimento do pó, com eficiência nominal de $80 \%$.

As emissões de $\mathrm{CO}_{2}, \mathrm{SO}_{\mathrm{x}}$ e material particulado foram retiradas de Socolof e Geibig (2005). Para avaliar a total substituição das soldas contendo chumbo na empresa em estudo, considerou-se a quantidade de solda livre de chumbo igual à da liga $63 \mathrm{Sn}-37 \mathrm{~Pb}$ (946 t) produzida pela Cast Metais e Soldas Ltda. A Tabela 7 apresenta os indicadores DALY obtidos para a produção de cada tipo de solda e os custos anuais calculados com a utilização do valor estatístico do impacto na vida humana para o Brasil (MIRAGLIA; SALDIVA, 2005). 
Tabela 6. Cálculo da quantidade de recursos não renováveis empregados na obtenção de $1 \mathrm{~kg}$ de solda $\left(\mathrm{kg}_{\mathrm{NR}} / \mathrm{kg}_{\mathrm{SOLDA}}\right)$ para a produção da Cast Metais e Soldas Ltda.

\begin{tabular}{lccc}
\hline Etapa do ciclo de vida & $\begin{array}{c}\mathbf{S n P b} / \\
\left(\mathbf{k g}_{\mathrm{NR}} / \mathbf{k g}_{\text {SOLDA }}\right)\end{array}$ & $\begin{array}{c}\mathbf{9 6 , 5 S n - 3 A g - 0 , 5 C u} / \\
\left(\mathbf{k g}_{\mathrm{NR}} / \mathbf{k g}_{\mathbf{S O L D A}}\right)\end{array}$ & SnAgCu / SnPb \\
\hline Extração/beneficiamento & 262 & 1078 & 4,1 \\
Manufatura & 66 & 69 & 1,0 \\
Subtotal & $\mathbf{3 2 8}$ & $\mathbf{1 1 4 7}$ & $\mathbf{3 , 5}$ \\
Uso/Aplicação & 35 & 21 & 0,6 \\
Descarte & 2 & 2 & 1,0 \\
Total no Ciclo de Vida & $\mathbf{3 6 5}$ & $\mathbf{1 1 7 0}$ & $\mathbf{3 , 2}$ \\
\hline
\end{tabular}

Adaptado de Socolof e Geibig (2005).

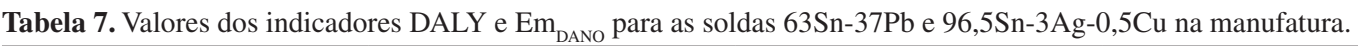

\begin{tabular}{lccc}
\hline Tipo de solda & DALY/(anos) & Em $_{\text {DANo }} /(\mathbf{s e j} / \mathbf{a n o})$ & US\$/ano \\
\hline 63Sn-37Pb & 2,9 & $4,28 \times 10^{16}$ & $22.330,00$ \\
96,5Sn-3Ag-0,5Cu & 0,4 & $6,02 \times 10^{15}$ & $3.080,00$ \\
\hline
\end{tabular}

Na manufatura, o indicador de anos de vida perdidos por inaptidão ou por morte prematura (DALY) mostra que a produção de soldas $63 \mathrm{Sn}-37 \mathrm{~Pb}$ causa uma perda de 2,9 anos, enquanto que, se esta solda fosse substituída pelas soldas livres de chumbo, a perda seria de 0,4 anos. Estes valores, convertidos em moeda corrente, representam US\$22.330,00 e US\$ 3.080,00, respectivamente, o que poderia ser interpretado como uma redução de aproximadamente $85 \%$ nos gastos com a saúde humana e os custos de hospitalizações causados pelas emissões da produção de $946 \mathrm{t}$ de solda.

A emergia correspondente ao dano para a saúde humana ou ao número de anos perdidos $\left(\mathrm{Em}_{\mathrm{DANO}}\right)$ devido à emissão dos contaminantes na manufatura é sete vezes maior para a produção de soldas $63 \mathrm{Sn}-37 \mathrm{~Pb}$. Esta emergia pode ser associada aos serviços ambientais utilizados para mitigar os efeitos das emissões da manufatura de soldas na saúde humana. $\mathrm{O}$ ambiente tem uma capacidade de fornecer recursos (emergia) para suporte das atividades humanas, mas quando esta emergia é utilizada, não estará disponível para outros processos. Desta forma, se a manufatura de soldas utiliza recursos diretos ou indiretos devido aos danos causados à saúde humana por suas emissões, outros processos estarão impedidos de utilizar estes recursos, o que pode comprometer a capacidade de suporte local ou global. A Figura 3 mostra os valores do indicador DALY na manufatura para cada emissão considerada e a emergia associada ao dano para a saúde humana para os dois tipos de solda. A contribuição das emissões de chumbo corresponde a $75 \%$ dos anos perdidos e da emergia do dano e a contribuição das emissões de $\mathrm{CO}_{2}$ é, também, significativa e corresponde a $22 \%$ do dano calculado. Desta forma, apesar de considerada a eficiência de $80 \%$ no desempenho dos EPIs e EPCs, observa-se que,

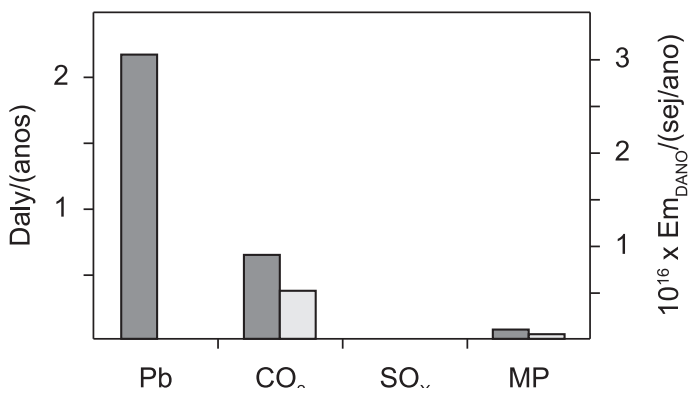

Figura 3. Valores do DALY e da emergia associada ao dano para a saúde do trabalhador na manufatura para cada emissão considerada. Em preto os valores para a solda $63 \mathrm{Sn}-37 \mathrm{~Pb}$ e em cinza os valores associados à solda $96,5 \mathrm{Sn}-3 \mathrm{Ag}-0,5 \mathrm{Cu}$.

na manufatura, é aconselhavel a produção das soldas livre de chumbo, o que pode explicar a pressão dos fabricantes de eletroeletrônicos japoneses e europeus pelo banimento das soldas à base de chumbo.

\subsubsection{Avaliação da substituição das soldas $63 \mathrm{Sn}-37 \mathrm{~Pb}$ com relação aos danos à saúde do trabalhador em todos os estágios do ciclo de vida do produto}

Considerando, por outro lado, que a produção de soldas livres de chubo utiliza $23 \%$ mais emergia que a produção das soldas à base de chumbo, é recomendável que uma avaliação mais ampla, incluindo outras etapas do ciclo de vida da fabricação das soldas, seja efetuada. O relatório de Socolof e Geibig (2005) mostra as quantidades de emissões de $\mathrm{CO}_{2}, \mathrm{SO}_{\mathrm{x}}$ e MP para o ar por quilograma de solda para todo o ciclo de vida dos dois tipos de solda, o que permite calcular o indicador DALY desde a extração das matérias-primas até o descarte do produto para a produção da Cast Metais 
e Soldas Ltda. Na Tabela 8, pode-se constatar que, mesmo considerando uma eficiência de $80 \%$ de EPIs e EPCs para todo o ciclo, o indicador DALY para as emissões de $\mathrm{CO}_{2}$ na etapa de extração/beneficiamento das soldas livres de chumbo é aproximadamente três vezes maior que aquele calculado para as emissões de chumbo na manufatura. Da mesma forma, observam-se aproximadamente 7,5 anos perdidos por inaptidão ou por morte prematura devido à emissão de material particulado na etapa de extração/beneficiamento das soldas livres de chumbo em contraste com os 4,36 anos perdidos pela emissão dos vapores de chumbo nas etapas de manufatura e uso/aplicação das soldas $63 \mathrm{Sn}-37 \mathrm{~Pb}$.

A Figura 4 mostra a comparação entre os valores do DALY para os dois tipos de solda, para cada etapa do ciclo de vida, considerando-se o total das emissões associadas à produção de $946 \mathrm{t}$ de cada tipo de solda, com e sem o uso de EPIs e EPCs. É importante ressaltar que a emissão de chumbo desde a extração até a manufatura reportada por Itsubo et al. (2003) está incluída na etapa de manufatura.

Para a solda $63 \mathrm{Sn}-37 \mathrm{~Pb}$, observa-se que os anos perdidos devido às emissões de chumbo para a atmosfera são mais importantes nas etapas de manufatura e aplicação da solda, mas que, na etapa de extração/beneficiamento, os anos perdidos devido às emissões de $\mathrm{CO}_{2}, \mathrm{SO}_{\mathrm{x}}$ e MP são comparáveis àqueles associados à emissão de vapores de chumbo nas etapas posteriores. No ciclo de vida das soldas livres de chumbo, observa-se, na etapa de extração/ beneficiamento, que o valor do DALY associado às emissões de $\mathrm{CO}_{2} \mathrm{SO}_{x}$ e MP é aproximadamente

Tabela 8. Valores dos indicadores DALY calculados para as soldas $63 \mathrm{Sn}-37 \mathrm{~Pb}$ e $96,5 \mathrm{Sn}-3 \mathrm{Ag}-0,5 \mathrm{Cu}$, considerando-se a eficiência de $80 \%$ dos EPIs e EPCs desde a extração até o descarte.

\begin{tabular}{lcccc}
\hline & \multicolumn{4}{c}{ DALY / (anos) } \\
\hline & $\mathbf{P b}$ & $\mathbf{C O}_{2}$ & $\mathbf{S O}_{\mathbf{x}}$ & $\mathbf{M P}(* *)$ \\
\hline $\mathbf{6 3 S n - 3 7 P b}$ & & & & \\
Extração/Beneficiamento & & 3,354 & 0,057 & 0,89 \\
Manufatura $\left(^{*}\right)$ & 2,18 & 0,651 & 0,01 & 0,072 \\
Uso/Aplicação $\left(^{*}\right)$ & 2,18 & 0,698 & 0,145 & 0,591 \\
Descarte & & 0,035 & 0,001 & 0,004 \\
\hline $\mathbf{9 6 , 5 S n - 3 A g - 0 , 5 C u}$ & & & & \\
Extração/Beneficiamento & - & 6,233 & 1,822 & 7,647 \\
Manufatura & - & 0,365 & 0,008 & 0,037 \\
Uso/Aplicação & - & 1,433 & 0,176 & 0,717 \\
Descarte & - & 0,042 & 0,001 & 0,004 \\
\hline
\end{tabular}

(*) emissões de chumbo na atmosfera de acordo com Itsubo et al. (2003).

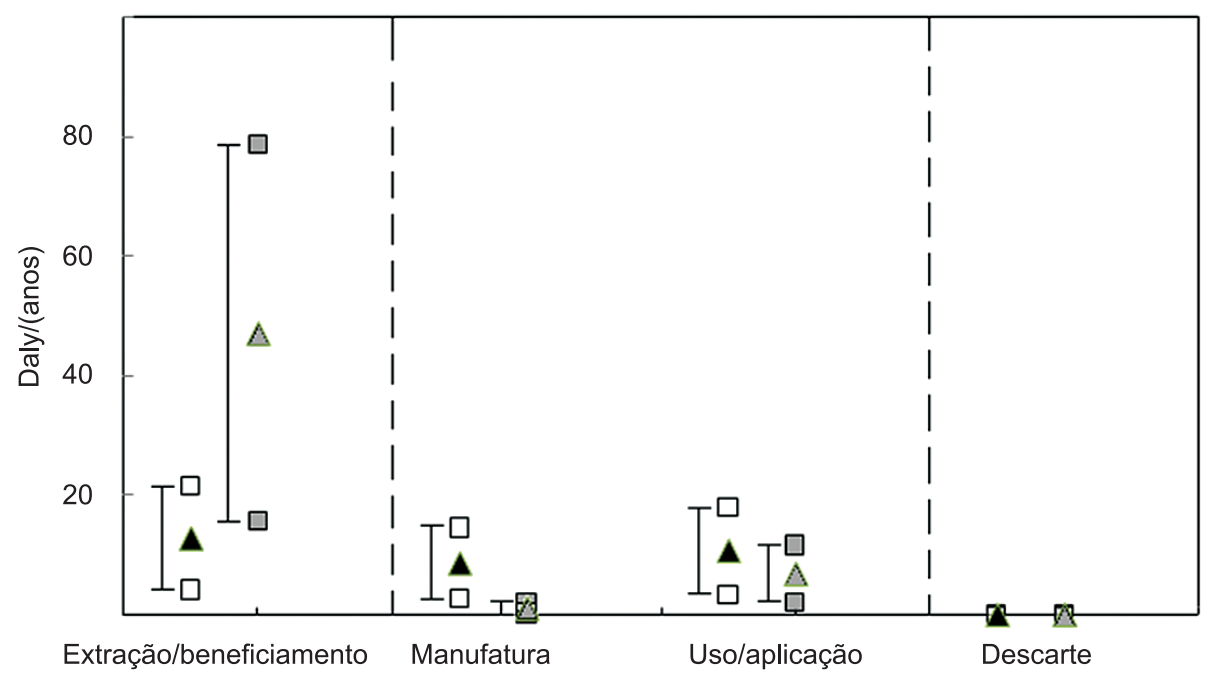

Figura 4. Comparação entre os valores do DALY para os dois tipos de solda e para cada etapa do ciclo de vida das soldas

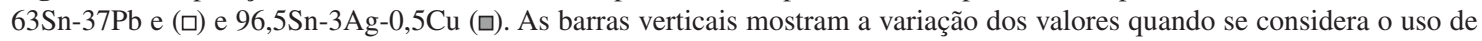
EPIs e EPCs com $80 \%$ de eficiência e sua ausência. Os triângulos representam a média das duas condições. MP: material particulado. 
Tabela 9. Valores dos indicadores DALY calculados considerando-se o total das emissões para todo o ciclo de vida para os dois tipos de solda e os correspondentes valores estimativos de vida e valores de emergia associada ao dano (Em DANO ).

\begin{tabular}{|c|c|c|c|c|c|c|}
\hline $\begin{array}{c}\text { Etapa do ciclo de } \\
\text { vida }\end{array}$ & $\begin{array}{l}\text { DALY/ } \\
\text { (anos) } \\
\text { com EPIs } \\
\text { e EPCs }\end{array}$ & $\begin{array}{c}\text { US\$/(ano) } \\
\text { com EPIs e } \\
\text { EPCs }\end{array}$ & $\begin{array}{c}\mathrm{Em}_{\mathrm{DANO}} \\
\times 10^{16} /(\text { sej/ano }) \\
\text { com EPIs e EPCs }\end{array}$ & $\begin{array}{c}\text { DALY/ } \\
(\text { anos) sem } \\
\text { EPIs e EPCs }\end{array}$ & $\begin{array}{c}\text { US\$/(ano) } \\
\text { sem EPIs e } \\
\text { EPCs }\end{array}$ & $\begin{array}{c}\mathrm{Em}_{\text {DANO }} \\
\times \mathbf{1 0}^{16} /(\text { sej/ano }) \\
\text { sem EPIs e EPCs }\end{array}$ \\
\hline
\end{tabular}

\begin{tabular}{lrrrrrr}
\hline $\mathbf{6 3 S n - 3 7 P b}$ & & & & & & \\
Extração/ & & & & & \\
Beneficiamento & 4,3 & $33.110,00$ & 6,34 & 21,505 & $165.588,50$ & 33,22 \\
Manufatura & 2,9 & $22.330,00$ & 4,28 & 14,565 & $112.150,50$ & 22,50 \\
Uso/Aplicação & 3,6 & $27.720,00$ & 5,31 & 18,07 & $139.139,00$ & 27,91 \\
Descarte & $<0,1$ & & & 0,2 & $1.540,00$ & 0,03 \\
& $\mathbf{1 0 , 9}$ & $\mathbf{8 3 . 9 3 0 , 0 0}$ & $\mathbf{1 6 , 0 8}$ & $\mathbf{5 4 , 3 4}$ & $\mathbf{4 1 8 . 4 1 8 , 0 0}$ & $\mathbf{8 3 , 9 4}$ \\
\hline $\mathbf{9 6 , 5 S n - 3 A g - 0 , 5 C u}$ & & & & & & 121,28 \\
Extração/ & $\mathbf{1 5 , 7}$ & $120.890,00$ & 23,17 & 78,51 & $604.527,00$ & 31,66 \\
Beneficiamento & 0,4 & $3.080,00$ & 0,59 & 2,05 & $15.785,00$ & 17,96 \\
Manufatura & 2,3 & $17.710,00$ & 3,39 & 11,63 & $89.551,00$ & 0,03 \\
Uso/Aplicação & & & 0,235 & $1.809,50$ & $\mathbf{1 4 2 , 7 8}$ \\
Descarte & $<0,1$ & $\mathbf{1 8 , 5}$ & $\mathbf{1 4 2 . 4 5 0 , 0 0}$ & $\mathbf{2 7 , 3 0}$ & $\mathbf{9 2 , 4 2 5}$ & $\mathbf{7 1 1 . 6 7 2 , 5 0}$ \\
& & & &
\end{tabular}

quatro vezes maior que o valor do DALY associado à emissão de chumbo na manufatura. Sem a utilização de equipamentos de proteção, o total de anos perdidos para o ciclo de vida da solda de estanho-chumbo apresenta um DALY total de 54,3 anos. Entretanto, totalizando-se os anos perdidos para a manufatura das soldas livres de chumbo obtém-se o valor de 92,4 anos, sendo que, deste valor, 40 anos correspondem às emissões de $\mathrm{CO}_{2}$ e 42 anos à emissão de material particulado. $\mathrm{O}$ total de anos perdidos por incapacidade ou morte prematura mostra-se maior para as soldas livres de chumbo, mesmo com a utilização de equipamentos de proteção individuais e coletivos. A Tabela 8 mostra o total de anos perdidos por morte prematura ou incapacidade para cada etapa do ciclo de vida dos dois tipos de solda e os correspondentes valores do valor estatístico do impacto na vida humana (MIRAGLIA; SALDIVA, 2005) e do indicador EmDANO.

Observa-se, na Tabela 9, que os gastos com a saúde humana e os custos de hospitalizações associados ao ciclo de vida da solda de $63 \mathrm{Sn}-37 \mathrm{~Pb}$ podem variar de US $\$ 20.000,00$ a US\$ $110.000,00$ por ano, dependendo da utilização ou da eficácia dos equipamentos de proteção individual e coletiva. Para a mesma etapa do ciclo de vida das soldas livres de chumbo, os gastos variam de US\$ 3.000,00 a US\$ $16.000,00$ por ano. A tomada de decisão, com base nesta análise, levaria à substituição total das ligas de chumbo, considerando a saúde do trabalhador mais importante que o uso de reservas naturais (Tabela 5).

Entretanto, se estas soldas forem totalmente substituídas por soldas livres de chumbo, os gastos com a saúde humana podem atingir mais de US $\$ 700.000,00$. Vale a pena ressaltar que, na etapa de manufatura há uma redução de mais de $80 \%$ nas possíveis despesas com saúde e hospitalizações. O mesmo ocorre na etapa de uso e aplicação, em que as despesas com saúde sofrem uma redução de aproximadamente $37 \%$. Entretanto, esta redução aparente é compensada por um grande aumento nos gastos anuais devidos aos impactos provenientes da etapa de extração/beneficiamento. A emergia associada ao dano causado à saúde humana pela emissão de poluentes na atmosfera durante o ciclo de vida das soldas $96,5 \mathrm{Sn}-3 \mathrm{Ag}-0,5 \mathrm{Cu}$ pode chegar a $1,42 \times 10^{18}$ sej/ano, o que corresponde à emergia necessária para manter produtivos 203 hectares por ano para a produção de café (OGURA, 2009) ou aproximadamente 1.700 hectares por ano para a produção de bambu (BONILLA et al., 2010).

\section{Conclusão}

A síntese em emergia foi utilizada para avaliar a produção dos três tipos de ligas na Cast Metais e Soldas Ltda. e determinar a intensidade de utilização dos recursos naturais no processo de produção destas ligas. O indicador de DALY foi empregado para avaliar os danos para a saúde humana causados pelas emissões ao ar. A emergia associada ao dano à saúde humana também foi calculada. Na manufatura:

- A avaliação em emergia mostrou que a utilização intensiva dos recursos naturais e, em especial, o uso de estanho, é o fator que contribui mais fortemente com o total em emergia. Entre os insumos utilizados, o GLP tem maior contribuição no total em emergia, para todas as ligas estudadas; 
- Em termos de eficiência na utilização de recursos, a solda $63 \mathrm{Sn}-37 \mathrm{~Pb}$ é a melhor opção, já que a fabricação das ligas livres de chumbo apresenta emergia total aproximadamente $23 \%$ superior; e

- O cálculo dos indicadores DALY mostra que pode haver cerca de 3 anos perdidos, devido à produção de solda $63 \mathrm{Sn}-37 \mathrm{~Pb}, \mathrm{com}$ $\mathrm{Em}_{\text {DANO }}=4,28 \times 10^{16}$ sej/ano. Para ligas livres de chumbo, há 0,41 anos perdidos associados à etapa de manufatura $\left(\mathrm{Em}_{\text {DANO }}=6,02 \times 10^{15}\right.$ sej/ano). O valor estatístico de vida mostra um custo anual de US\$22.330,00 para a liga $63 \mathrm{Sn}-37 \mathrm{~Pb}$, que é aproximadamente sete vezes maior que o obtido para a produção de ligas livres de chumbo.

A avaliação efetuada na etapa de manufatura leva a resultados ambíguos. De um lado, a produção de soldas $63 \mathrm{Sn}-37 \mathrm{~Pb}$ mostra-se mais eficiente no uso de recursos naturais e, levando-se em conta este resultado, seria recomendável optar pela continuidade da produção das soldas contendo chumbo. Por outro lado, o cálculo do indicador DALY e da Em DANO mostram que a opção pelas ligas livres de chumbo é preferível.

Quando se avalia apenas uma parte da cadeia produtiva (manufatura), os resultados obtidos não permitem decidir, com base nos indicadores quantitativos, qual a solda mais adequada para evitar o impacto. Tomando-se uma decisão subjetiva e antropocêntrica, pode-se optar pela substituição total das soldas de estanho-chumbo pelas soldas livres de chumbo, levando em consideração que a saúde humana é mais importante que a preservação dos recursos naturais. Esta, de fato, foi a decisão tomada pela Comunidade Europeia e pelo Japão, que concentram as atividades de produção de solda e montagem de circuitos eletrônicos.

Entretanto, quando a avaliação é ampliada para levar em consideração todo o ciclo de vida da produção dos dois tipos de solda, observa-se que, na etapa de extração/beneficiamento, a produção das soldas livres de chumbo é menos eficiente no que se refere ao uso de recursos naturais não renováveis e, também, causa maior dano à saúde humana. Este dano ocorre nos locais em que se extrai e beneficia o minério necessário para a produção destas soldas, geralmente em países em desenvolvimento ou países que têm sua economia baseada na extração e exportação de recursos naturais não renováveis.

\section{Referências}

ALMEIDA, C. M. V. B. et al. Emergy as a tool for Ecodesign: evaluating materials selection for beverage packages in Brazil. Journal of Cleaner Production, v. 18, n. 1, p. 32-43, 2010a.
ALMEIDA, C. M. V. B. et al. Identifying improvements in water management of bus-washing stations in Brazil. Resources, Conservation and Recycling, v. 54, n. 11, p. 821-831, 2010b. http://dx.doi.org/10.1016/j. resconrec.2010.01.001

ANDRAE, N. S. G. et al. Life cycle assessment of Japanese high-temperature condutive adhhesives. Environmental Science Technology, v. 42, p. 3084-3089, 2008. http:// dx.doi.org/10.1021/es0709829

BARRELLA, F. A.; ALMEIDA, C. M. V. B.; GIANNETTI, B. F. Ferramenta para tomada de decisão considerando a interação dos sistemas de produção e o meio ambiente. Produção, v. 15, n. 1, p. 87-101, 2005.

BONILLA, S. H. et al. Sustainability assessment of a giant bamboo plantation in Brazil: exploring the influence of labor, time and space. Journal of Cleaner Production, v. 18, n. 1, p. 83-91, 2010. http://dx.doi.org/10.1016/j. jclepro.2009.07.012

BROWN, M. T.; BURANAKARN, V. Emergy indices and ratios for sustainable material cycles and recycle options. Resources, Conservation and Recycling, v. 44, n. 6, p. 419-419, 2003.

CARUSO, C. et al. Emergy based analysis of Italian electricity production system. Journal of Thermal Analysis and Calorimetry, v. 66, p. 265-272, 2001. http://dx.doi.org/10.1023/A:1012412420744

CIOCCI, R.; PECHT, M. Impact of environmental regulations on green electronics manufacture. Microelectronics International, v. 23, n. 2, p. 45-50, 2006. http://dx.doi. org/10.1108/13565360610659716

COELHO, O.; ORTEGA, E.; COMAR, V. Balanço de Energia do Brasil. UNICAMP, 2002. Disponível em: $<$ http:www.fea.unicamp.br-docente-ortega-livro-C05Brasil-COC.pdf>. Acesso em: 03 mar. 2009.

COHEN, M. J.; BROWN, M. T.; SHEPERD, K. D. Estimating the environmental costs of soil erosion at multiple scales in Kenya using emergy synthesis. Agricultural Ecosystems \& Environment, v. 114, p. 249-269, 2007. http://dx.doi.org/10.1016/j.agee.2005.10.021

ROMM, D.; ABBOTT, D. Pb-free solder joint evaluation. Surface mount technology, v. 12, p. 84-88, 1998.

DEUBZER, O. et al. Lead-free soldering, toxicity, energy and resource consumption. Berlin: Fraunhofer IZM, 2001. p. 290-295.

FUJIMO, M.; SUGA, T. Evaluation of energy consumption of lead-free soldering process. In: ECODESIGN INTERNATIONAL SYMPOSIUM ON ENVIRONMENTALLY CONSCIOUS DESIGN AND INVERSE MANUFACTURING, 3., 2003, Toquio. Proceedings... IEEE, 2003. p. 831-835. http://dx.doi. org/10.1109/ECODIM.2003.1322782

GARCIA, L. R. et al. Correlação entre propriedades mecânicas e arranjo dendrítico de ligas Sn-Zn utilizadas em solda sem a presença de chumbo. Revista Matéria, v. 14, n. 2, 2009.

GIANNETTI, B. F.; ALMEIDA, C .M. V. B.; BONILLA, S. H. Comparing emergy accounting with well-known sustainability metrics: The case of Southern Cone Common Market, Mercosur. Energy Policy, v. 38, n. 7, p. 3518-3526, 2010. http://dx.doi.org/10.1016/j. enpol.2010.02.027 
GIANNETTI, B. F.; BARRELLA, F. A.; BONILLA, S. H. Aplicações do diagrama emergético triangular na tomada de decisão ecoeficiente. Produção, v. 17, n. 2, p. 246-262, 2007.

GIANNETTI, B. F. et al. The reliability of experts' opinions in constructing a composite environmental index: The case of ESI 2005. Journal of Environmental Management, v. 90, n. 8, p. 2448-2459, 2009. PMid:19285781. http:// dx.doi.org/10.1016/j.jenvman.2008.12.018

ITSUBO, N. et al. Damage assessment of human health of lead-free based on endpoint-tipe lcia metodology.In: ECODESIGN INTERNATIONAL SYMPOSIUM ON ENVIRONMENTALLY CONSCIOUS DESIGN AND INVERSE MANUFACTURING, 3., 2003, Toquio. Proceedings... IEEE, 2003. p. 836-838.

$\mathrm{KU}$, A. et al. Lead-free solders: issues of toxicity, availability and impacts of extraction. In: IEEE ELECTRONIC COMPONENTS AND TECHNOLOGY CONFERENCE PROCEEDINGS, 53., 2003, New Orleans. Proceedings... IEEE, 2003. p. 47-53.

MA, J.; CHEN, G. Lead-free solder materials for sustainable development of green electronics in China. In: INTERNATIONAL CONFERENCE ON ELECTRONIC PACKAGING TECHNOLOGY, 6., 2005, Beijing. Proceedings... IEEE, 2005. p. 1-6.

MADUREIRA, M. A. Avaliação em emergia para tomada de decisão na substituição das soldas à base de estanho e chumbo. 2009. Dissertação (Mestrado em Engenharia de Produção)-Universidade Paulista, São Paulo, 2009. Disponível em: <http://www. advancesincleanerproduction.net/papers/dissertations/ madureira_ma.pdf>.

MIRAGLIA, S. G. K.; SALDIVA, P. H. N. An evaluation of air pollution health impacts and costs in São Paulo, Brazil. Environmental Management, v. 35, n. 5, p. 667-676, 2005. PMid:15920669. http://dx.doi. org/10.1007/s00267-004-0042-9

ODUM, H. T.; BROWN, M. T.; BRANDT-WILLIAMS, S. Handbook of Emergy Evaluation: a compendium of data for emergy computation issued in a series of folios. Gainesville: University of Florida, Center for Environmental Policy, Environmental Engineering Sciences, 2000. Fólio \# 1: Introduction and Global Budget.

ODUM, H. T. Environmental accounting: emergy and environmental decision making. New York: John Wiley \& Sons Inc., 1996.

OGURA, Y. Estudo da sustentabilidade ambiental da produção de café. 2009. Dissertação (Mestrado em Engenharia de Produção)-Universidade Paulista, São Paulo, 2009.

OKAMOTO, M. et al. Overall Technological Results of IMS-EFSOT. Japanese Project in Environmental Impact of Lead-Free Soldering, p. 554-558, 2005.
PERASSI, N. C. P. Manual de soldas brandas: estanho - chumbo: A teoria da Soldagem (Soldering). Gráfica de Edições Paulinas, 1994.

REUTER, M. N.; EVERHOEF, W. V. A dynamic model for the assessment of the replacement of lead in solders. Journal of Electronic Materials, v. 33, n. 12, p. 1567-1580, 2004. http://dx.doi.org/10.1007/ s11664-004-0100-3

SEGERBERG, T.; HEDEMALM, P. Life cycle assessment of tin-lead solder and silver-epoxy conductive adhesive. In: IEEE INTERNATIONAL SYMPOSIUM ON ELECTRONICS AND THE ENVIRONMENT, 1996, Dallas. Proceedings... IEEE, 1996. p. 64-65.

SOCOLOF, M. L.; GEIBIG, J. R. Life-cycle impacts of lead and lead-free solder used in wave. In: IEEE INTERNATIONAL SYMPOSIUM ON ELECTRONICS AND THE ENVIRONMENT, 2005, Bethesda. Proceedings... IEEE, 2005. p. 96-101.

TILLEY, D. R. Emergy basis of forest systems. 1999. 310 f. Thesis (Doctoral)-University of Florida, 1999.

TURBINI, L. J. Processing and material issues related to lead-free soldering. Journal of Materials Science: Materials in Electronics, v. 18, n. 1-2, p. 147-154, 2007. http://dx.doi.org/10.1007/s10854-006-9014-6

TURBINI, L. J. et al. Examining the environmental impact of lead-free soldering alternatives. In: IEEE INTERNATIONAL SYMPOSIUM ON ELECTRONICS AND THE ENVIRONMENT, 2000, New York. Proceedings... IEEE, 2000. p. 146-153.

UKIDWE, N. U.; BAKSHI, B. R. Thermodynamic accounting of ecosystem contribution to economic sectors with application to 1992 U.S. economy. Environmental Science \& Technology, v. 38, p. 4810-4827, 2004. http://dx.doi.org/10.1021/es035367t

ULGIATI, S.; BROWN, M. T. Quantifying the environmental support for dilution and abatement of process emissions - The case of electricity production. Journal of Cleaner Production, v. 10, p. 335-348, 2002. http:// dx.doi.org/10.1016/S0959-6526(01)00044-0

WANG, L.; ZHANG, J.; NI, W. Emergy evaluation of combined heat and power plant eco-industrial park (CHP plant EIP). Resources, Conservation and Recycling, v. 189 , p. 233-240, 2005.

ZHANG, X. et al. Emergy evaluation of the sustainability of Chinese steel production during 1998-2004. Journal of Cleaner Production, v. 17, p. 1030-1038, 2009. http:// dx.doi.org/10.1016/j.jclepro.2009.02.014

ZHOU, X.; SCHOENUNG, J. M. An integrated impact assessment and weighting methodology: evaluation of the environmental Consequences of Lead-Free Solder Alternatives. Journal of Environmental Management, v. 83, n. 1, p. 1-24, 2007. PMid:16714079. http://dx.doi. org/10.1016/j.jenvman.2006.01.006 